\title{
Investigation on the characteristics and management of dental waste in Urmia, Iran
}

\author{
Ali Koolivand · Fathollah Gholami-Borujeni • \\ Heshmatollah Nourmoradi
}

Received: 8 August 2013/ Accepted: 8 June 2014/Published online: 1 July 2014

(C) The Author(s) 2014. This article is published with open access at Springerlink.com

\begin{abstract}
The objective of this study was to identify the components, composition, generation rate and management of dental waste in Urmia, Iran. Fifteen dental centers including eight general dental offices, five specialist dental offices and two dental clinics were selected and two samples were taken from each office. Then, the wastes were manually separated in 31 components and weighted. The results showed that total dental waste generation in all general dental offices, specialist dental offices and dental clinics were 58.94, 17.92 and $10.22 \mathrm{~kg} /$ day, respectively. Domestic, potentially infectious, toxic and chemical and pharmaceutical waste also constituted 35.46, 34.24, 11.83 and $5.56 \%$ of total waste, respectively. Only 11 components including blood-contaminated paper towel, salivacontaminated paper towel, saliva-contaminated cotton, extracted teeth, blood-contaminated gauze, inseparable components, nylon glove, tongue blade, latex glove, saliva ejector and blood-contaminated cotton constituted more than $80 \%$ of total infectious waste generation. There was
\end{abstract}

\footnotetext{
A. Koolivand

Department of Environmental Health Engineering, School of Health, Arak University of Medical Sciences, Arāk, Iran

F. Gholami-Borujeni ( $\square)$

Social Determinants of Health Research Center, Urmia University of Medical Sciences, PO Box: 5756116111, Urmia, Iran

e-mail: Gholami_b_f@yahoo.com; fgholami@umsu.ac.ir

F. Gholami-Borujeni

Department of Environmental Health Engineering, School of Health, Urmia University of Medical Sciences, Urmia, Iran

H. Nourmoradi

Department of Environmental Health Engineering, School of Health, Ilam University of Medical Sciences, Ilam, Iran
}

no management program (waste minimization, separation, reuse and recycling) in the dental offices. Source reduction, separation, reuse and recycling activities should be conducted to decrease the hazards of dental wastes. It is also suggested that each fraction of dental waste should be separately collected and disposed in the accordance with its related criteria.

Keywords Dental waste $\cdot$ Infectious waste $\cdot$ Chemical and pharmaceutical waste Toxic waste $\cdot$ Urmia

\section{Introduction}

Health care wastes are defined as discarded materials from health care activities that have the potential of transmitting infectious agents to humans [1]. There is no specific attention to health care waste in comparison with other types of wastes, especially in developing countries [2, 3]. The management of health care waste as a complicated issue requires training, awareness, and financial resources $[4,5]$. Dentistry is a part of health care services and dental waste management is a category that needs to be organized [6]. Although dental centers are considered as a minor source of health care waste, but they generate a certain amount of hazardous waste. Dental offices produce a variety of wastes such as domestic-type, infectious, toxic, chemical and pharmaceutical wastes. Each fraction would require a specific approach for collection, treatment and disposal $[6,7]$.

Domestic-type or general waste comprises components such as paper, cardboard and plastics that is not endanger for human and animal health or the environment. This fraction, if well segregated, can be collected and disposed of with municipal solid waste [8, 9]. 
Infectious wastes include sharps and discarded materials or equipments that have exposed to blood and its derivatives $[9,10]$. Since the infectious waste is classified as hazardous, its safe management is necessary to avoid environmental and public health problems [11, 12]. Dental centers also produce certain amount of metals and chemical compounds that have health hazards to the human and environment [6]. The common sources of such hazardous waste at dental clinics include dental amalgam, chemical disinfectants and fixer solutions [13, 14]. Dental amalgam is a solid stable restorative material that has been used in dental applications for about 200 years. [15, 16]. Amalgam is regulated as a hazardous waste because more than $70 \%$ of its mass is mercury and silver. These metals can accumulate in food chain and impose adverse health risks $[17,18]$. There has been increasing challenges on the waste that is generated by dental centers. The harmful effects of such waste may cause serious human and environmental problems if not managed properly. Identification of the quantity and composition of dental waste is necessary to achieve suitable management options [19]. For this reason, there have been many studies on dental waste in different countries [8, 1925]. Most of them have concentrated on waste composition. For example, Kizlary et al. [8] reported that dental waste consisted of infectious waste, $94.7 \%$, noninfectious waste, $2.0 \%$ and domestic-type waste $3.3 \%$ by weight. Ozbek and Sanin [20] also reported that rubber gloves and paper are two major components of the dental solid waste in eight clinics of a dental school. On the other hand, the management aspect of the waste was focused in some studies [22-25]. They all deduced that waste management activities were poor and unsuitable.

In Iran, the problem of dental waste is still largely unsolved, primarily due to the absence of specific legislation focused on dental waste. In the most areas of Iran, dental waste is collected along with municipal solid waste and is disposed in uncontrolled landfills. Based on our knowledge, the first and only reported research on dental waste in Iran was conducted by Nabizadeh et al. [19]. It was reported from the study that the dental waste consisted of $71.15 \%$ domestictype waste, $21.4 \%$ potentially infectious waste, $7.26 \%$ chemical and pharmaceutical waste and $0.18 \%$ toxic wastes.

Therefore, the present study was performed to identify the components, composition and generation rate of dental waste and associated management practices in dental offices in Urmia, Iran. In addition to private dental centers, the dental clinics were also investigated in the present study.

\section{Methodology}

\section{Selection of dental offices}

This study was conducted on the dental centers of Urmia city, located in the northwest of Iran, in 2013. In Urmia with a population of 680288 citizens, there are 248 general dentist offices, 33 specialist dentist offices and 3 dental clinics in the city. Some primitive treatments such as restorative (fillings, crowns, bridges), extraction of teeth, as well as performing examinations, radiographs (X-rays) and diagnosis are done in the general dental offices. They can also prescribe medications such as antibiotics and any other drugs used in patient management. There are nine dental specialties in Iran including endodontics, oral and maxillofacial pathology, oral and maxillofacial radiology, dental implantation, oral and maxillofacial surgery, orthodontics, pediatric dentistry, periodontics, and prosthodontics. One of or any of these activities is done in each specialist dental offices and dental clinics, respectively. Fifteen dental centers including eight general dental offices, five specialist dental offices and two dental clinics were randomly selected. From each office, two samples were taken at the end of successive working day on Monday and Tuesday.

\section{Waste collection and separation}

Sample collection was carried out at night as working time was over. The samples were separately transferred to the waste storage room and then manually separated into four sub-fractions with 31 components (Table 1) [26]. Each sub-fraction was weighed using a laboratory scale (Model PM Mettler 4000) within $10 \mathrm{~h}$ after the sampling.

\section{Data collection}

Total daily generation of dental waste $(W)$ in all the dental offices were calculated based on a simple procedure as below. The $w$ in these equations is the waste generation in each sampling day. As well, the Figs. 1, 2, 3, 4 and 5 are the total number of samples in each dental center.

$$
\begin{aligned}
& W_{\text {general dentist offices }}=\left[\left(w_{1}+w_{2}+\cdots+w_{16}\right) / 16\right] \times 248 \\
& W_{\text {specialist dentist offices }}=\left[\left(w_{1}+w_{2}+\cdots+w_{10}\right) / 10\right] \times 33 \\
& W_{\text {dental clinics }}=\left[\left(w_{1}+w_{2}+\cdots+w_{4}\right) / 4\right] \times 3
\end{aligned}
$$

Management activities were investigated by means of a structured questionnaire. Dentists were asked about waste production, separation, reuse, recycling, collection and disposal. Furthermore, dentists who use X-ray units in their 
Table 1 Classification of dental waste components

\begin{tabular}{|c|c|}
\hline Waste fractions & Waste components \\
\hline Potentially infectious wastes & $\begin{array}{l}\text { Blood-contaminated paper towel, saliva-contaminated paper towel, blood-contaminated gauze, saliva- } \\
\text { contaminated gauze, blood-contaminated cotton, saliva-contaminated cotton, blood-contaminated dental roll, } \\
\text { saliva-contaminated dental roll, nylon glove, latex glove, syringe, saliva ejector, sharps and needles, extracted } \\
\text { teeth, dental mirror, surgical blades, tongue blade, inseparable components }\end{array}$ \\
\hline $\begin{array}{l}\text { Chemical and } \\
\text { pharmaceutical wastes }\end{array}$ & Used medicine ampoules, wax, dental impression material, calcium hydroxide \\
\hline Toxic wastes & $\begin{array}{l}\text { Amalgam-contaminated paper towel, amalgam-contaminated gauze, amalgam-contaminated cotton, amalgam- } \\
\text { contaminated dental rolls, film packet's lead foil, amalgam particles, radiography film, inseparable components }\end{array}$ \\
\hline Domestic-type wastes & The residual components \\
\hline
\end{tabular}

offices were asked about the handling and disposal of the processing solutions. In addition, some questions focused on the presence of puncture-resistant containers in the offices and the personnel in charge of their collection from the clinic.

\section{Results and discussion}

Waste generation

As seen from Fig. 1, total dental waste production in the dental offices is $87.09 \mathrm{~kg} /$ day. General dental offices, specialist dental offices and dental clinics are responsible for $67.68 \%$ (58.94 kg/day), $20.58 \%$ (17.92 kg/day) and $11.74 \%$ (10.22 kg/day) of this amount, respectively.

Percentages of different fractions of the waste in dental centers are shown in Figs. 2, 3, 4 and 5. Domestic-type, potentially infectious, toxic and chemical and pharmaceutical waste constituted $40.72,39.32,13.58$ and $6.38 \%$ of total waste production $(87.09 \mathrm{~kg} /$ day $)$, respectively. The similar study in Iran [19] showed that the percentages of

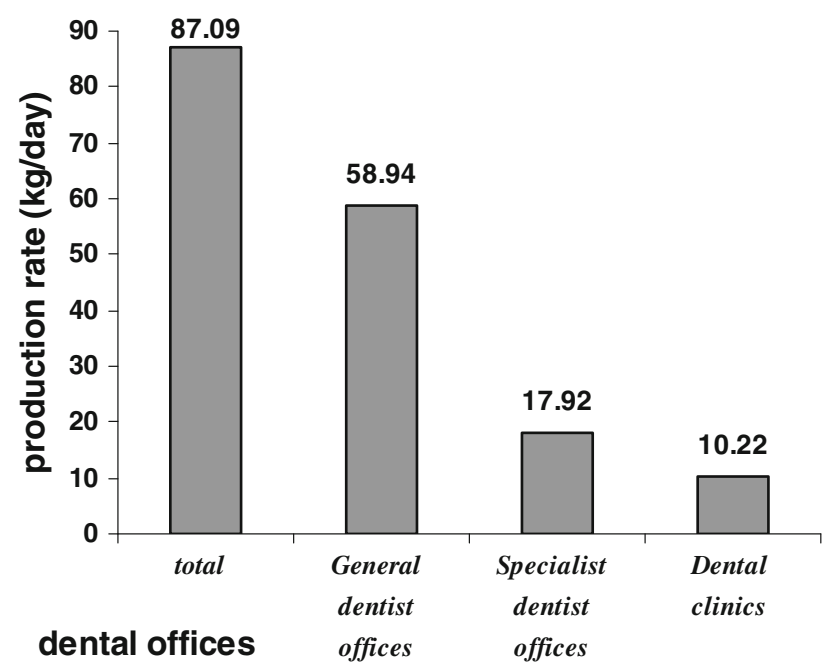

Fig. 1 Production rate of dental waste in the dental centers domestic-type, potentially infectious, toxic and chemical and pharmaceutical wastes were 71.15, 21.40, 0.018 and $7.26 \%$, respectively. Different fractions of dental waste in the general dentist offices (Fig. 3) showed that the percentages of domestic-type, potentially infectious, toxic and

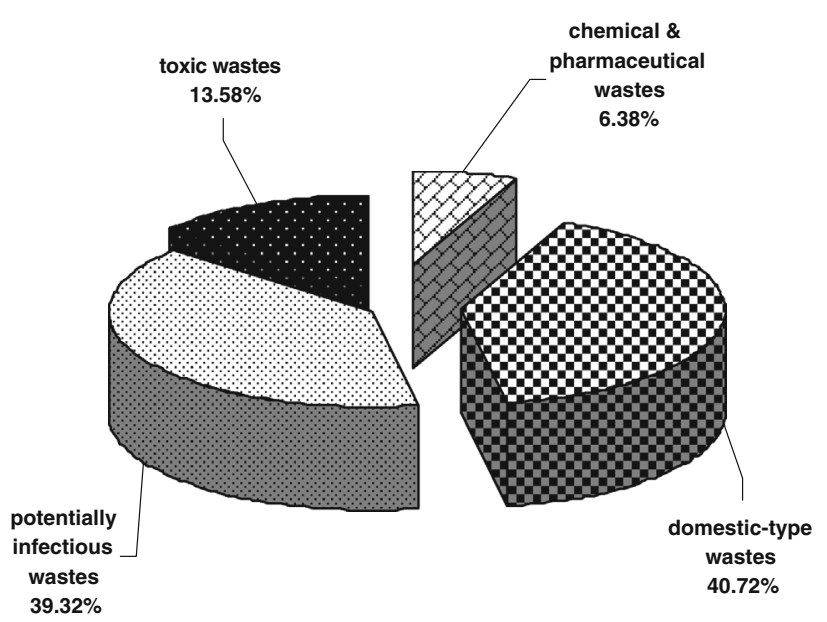

Fig. 2 Different fractions of dental waste in the total dental offices

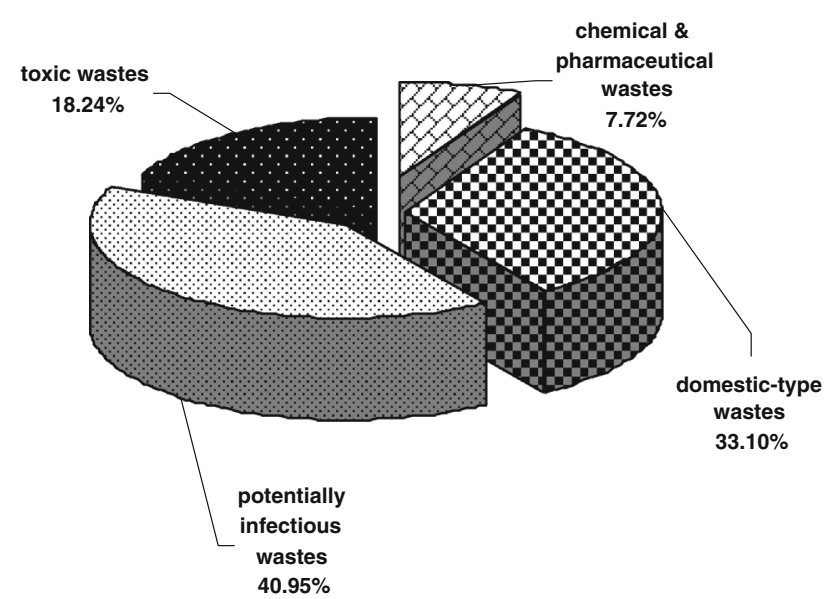

Fig. 3 Different fractions of dental waste in the general dentist offices 


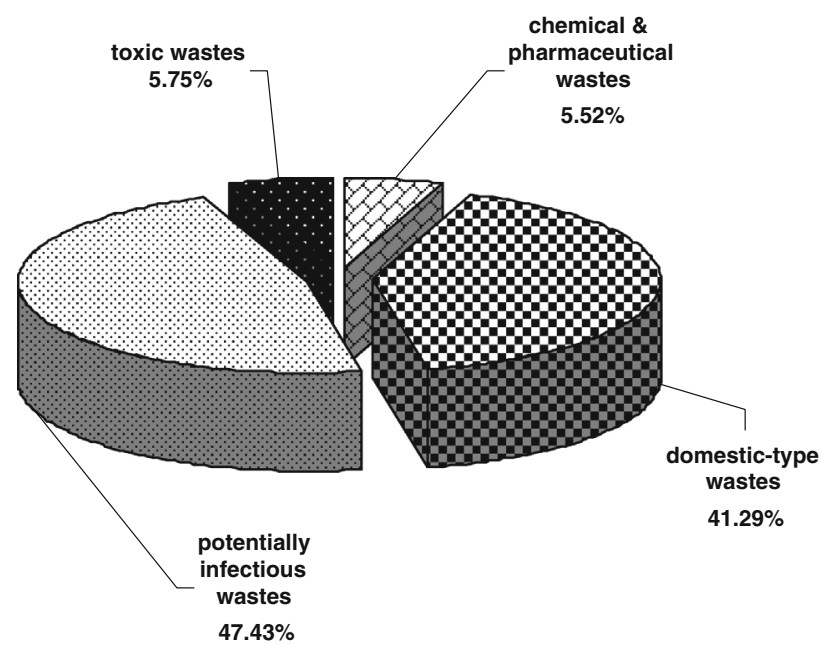

Fig. 4 Different fractions of dental waste in the specialist dentist offices

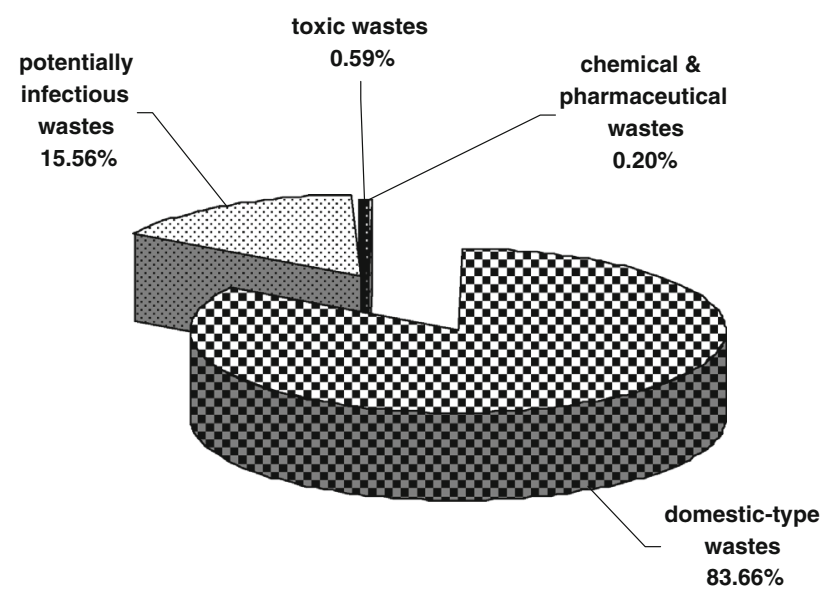

Fig. 5 Different fractions of dental waste in the dental clinics

chemical and pharmaceutical wastes were 33.1, 40.95, 18.24 and $7.72 \%$, respectively. Different fractions of dental waste in the specialist dentist offices (Fig. 4) showed that the percentages of domestic-type, potentially infectious, toxic and chemical \& pharmaceutical wastes were $41.29,47.43,5.75$ and $7.72 \%$, respectively. According to these results, in general dentist offices, percentages of potentially infectious waste are more than other fractions and need management to avoid the health effects of them.

Dental waste composition is influenced by different factors such as the type of study, type and procedure of selected dental centers and the definition of infectious waste. It is obvious from the present study (Fig. 5) that more than $80 \%$ of the waste comprises domestic-type and potentially infectious fractions in dental clinics. Kizlary et al. [8] reported that 94.7 and $3.3 \%$ of dental waste
Table 2 Production rate of infectious waste components in the dental centers

\begin{tabular}{lccl}
\hline Components & $\begin{array}{l}\text { Rate } \\
\text { (kg/day) }\end{array}$ & Percent & $\begin{array}{l}\text { Cumulative } \\
\text { percent }\end{array}$ \\
\hline Blood-contaminated paper towel & 3.88 & 11.33 & 11.33 \\
Saliva-contaminated paper towel & 3.79 & 11.08 & 22.40 \\
Saliva-contaminated cotton & 2.73 & 7.98 & 30.38 \\
Extracted teeth & 2.62 & 7.65 & 38.03 \\
Blood-contaminated gauze & 2.61 & 7.61 & 45.64 \\
Inseparable components & 2.49 & 7.28 & 52.92 \\
Nylon gloves & 2.40 & 7.02 & 59.95 \\
Tongue blade & 2.31 & 6.76 & 66.71 \\
Latex gloves & 2.20 & 6.42 & 73.12 \\
Saliva ejectors & 2.01 & 5.87 & 78.99 \\
Blood-contaminated cotton & 1.71 & 5.00 & 83.99 \\
Syringes & 1.61 & 4.70 & 88.69 \\
Saliva-contaminated gauze & 1.39 & 4.06 & 92.75 \\
Sharps and needles & 0.90 & 2.64 & 95.39 \\
Saliva-contaminated dental rolls & 0.68 & 2.00 & 97.39 \\
Blood-contaminated dental rolls & 0.53 & 1.55 & 98.94 \\
Dental mirror & 0.32 & 0.93 & 99.86 \\
Surgical blades & 0.05 & 0.14 & 100 \\
Sum & 34.24 & 100 & - \\
\hline
\end{tabular}

produced by dental centers were potentially infectious and domestic type, respectively. Vieira also showed that infectious $(24.3 \%)$, non-infectious $(48.1 \%)$ and domestictype $(27.6 \%)$ wastes were the major constituents of the dental waste [21]. Therefore, the separation of potentially infectious waste and domestic-type waste is required to prevent infected waste mixed into the municipal solid waste.

Tables 2, 3 and 4 show the percentage of components in the different fractions of dental waste. As shown, only 11 components constituted more than $80 \%$ of total infectious waste generation in the dental centers. These components including blood-contaminated paper towel, saliva-contaminated paper towel, saliva-contaminated cotton, extracted teeth, blood-contaminated gauze, inseparable components, nylon glove, tongue blade, latex glove, saliva ejector and blood-contaminated cotton. Sudhakar and Chandrashekar [22] reported that large amounts of dental waste were generated during dental practice, such as cotton, plastic, latex, and glass and most of them were contaminated with body fluids. Ozbek and Sanin [20] indicated that gloves constituted the highest percentage of dental waste (about $35 \%$ by weight) in Turkey. According to Table 3, production rate of toxic waste components in the Urmia dental centers is $11.1 \mathrm{~kg} / \mathrm{day}$ and production rate of chemical \& pharmaceutical waste in the Urmia dental centers is $5.56 \mathrm{~kg} /$ day (Table 4). 
Table 3 Production rate of toxic waste components in the dental centers

\begin{tabular}{llll}
\hline Components & $\begin{array}{l}\text { Rate } \\
\text { (kg/day) }\end{array}$ & Percent & $\begin{array}{l}\text { Cumulative } \\
\text { percent }\end{array}$ \\
\hline Radiography film & 2.75 & 24.75 & 24.75 \\
Inseparable components & 2.06 & 18.60 & 43.35 \\
$\begin{array}{l}\text { Film packet's lead foil } \\
\text { Amalgam-contaminated }\end{array}$ & 1.76 & 15.87 & 59.22 \\
$\quad 1.55$ & 14.01 & 73.23 \\
$\quad$ paper towel & & & \\
$\begin{array}{l}\text { Amalgam-contaminated } \\
\text { cotton }\end{array}$ & 0.94 & 8.51 & 81.73 \\
$\begin{array}{l}\text { Amalgam-contaminated } \\
\text { gauze }\end{array}$ & 0.92 & 8.27 & 90.01 \\
$\begin{array}{l}\text { Amalgam particles } \\
\text { Amalgam-contaminated }\end{array}$ & 0.84 & 7.55 & 97.56 \\
$\quad$ dental rolls & 0.27 & 2.44 & 100 \\
\begin{tabular}{l} 
Sum \\
\hline
\end{tabular} & 11.10 & 100 & - \\
\hline
\end{tabular}

Table 4 Production rate of chemical and pharmaceutical waste in the dental centers

\begin{tabular}{llll}
\hline Components & $\begin{array}{l}\text { Rate } \\
(\mathrm{kg} / \mathrm{day})\end{array}$ & Percent & $\begin{array}{l}\text { Cumulative } \\
\text { percent }\end{array}$ \\
\hline Dental impression material & 3.99 & 71.71 & 71.71 \\
Used medicine ampoules & 0.71 & 12.73 & 84.44 \\
Calcium hydroxide & 0.62 & 11.22 & 95.66 \\
Wax & 0.24 & 4.34 & 100 \\
Sum & 5.56 & 100 & - \\
\hline
\end{tabular}

Waste production rate in general and specialist dentist offices in Urmia was calculated as 31.56 and $77.71 \mathrm{~g} /$ day/ patient, respectively. Nabizadeh et al. [19] reported that per capita of dental waste in general and specialist dentist offices in Hamedan was 48.72 and $65.87 \mathrm{~g} /$ day/patient, respectively. Comparison of these two results in Iran with other countries such as Greece with a per capita of $513 \mathrm{~g} /$ day/person indicates that the generation rate of dental waste in Iran is very low [8]. The generation rate of dental waste depends on various factors such as economy, dentistry procedures and the type of used materials. Although the amount of dental waste is small in comparison with municipal solid waste, the treatment and disposal management of dental waste due to its hazardous characteristics is necessary. Our findings (Table 5) indicated that there was no effective activity for waste minimization, separation, reuse and recycling in the dental centers. Management of sharps, potentially infectious and other hazardous dental wastes was also not proper and these items were collected and disposed along with domestic waste. The results are in accordance with the Darwish and Al-Khatib and Nazar et al. studies [23, 24]. The Indian study conducted by
Table 5 Waste management condition in the dental offices and clinics

\begin{tabular}{ll}
\hline Management options & General dentist offices \\
\hline Waste reduction program & $100 \% \mathrm{NP}^{\mathrm{a}}$ \\
Waste separation program & $100 \% \mathrm{NP}^{\mathrm{a}}$ \\
Waste recycling program & $100 \% \mathrm{NP}^{\mathrm{a}}$ \\
Silver recovery & $100 \% \mathrm{NP}^{\mathrm{a}}$ \\
Mercury recovery & $100 \% \mathrm{NP}^{\mathrm{a}}$ \\
Amalgam recycling & $100 \% \mathrm{NP}^{\mathrm{a}}$ \\
Film packet recycling & $100 \% \mathrm{NP}^{\mathrm{a}}$ \\
Fixer solution recycling & $100 \% \mathrm{NP}^{\mathrm{a}}$ \\
Developer solution recycling & $100 \% \mathrm{NP}^{\mathrm{a}}$ \\
Sharps management & $90 \%$ by safety box \\
& $10 \%$ by trash disposal \\
Method of equipment & $40 \%$ yes \\
sterilization & $53 \%$ by oven \\
& $30 \%$ by autoclave \\
\end{tabular}

$N P$ not performed

Sudhakar and Chandrashekar showed that many dental centers $(35.7 \%)$ dispose their dental waste without segregation and disinfection into municipal solid waste [22].

Management activities

Our findings also indicated that improper disposal of sharps and amalgam was widespread among the clinics as these items were discarded with the general garbage. Kontogianni et al. [25] showed that there was no organized dental waste management program in private dental units of Thessalonica in Greece. Sharps, because of the blood contact, are considered as highly hazardous health care waste. Therefore, it should be placed in safety box or special thick wall containers, suitably labeled and finally incinerated. The scrap amalgam and amalgam filling in the removed teeth along with the amalgam lost to the wastewater stream during the dental practices; require strict control programs. Due to the absence of silver recycling companies or silver recovery units in Iran, X-ray fixer solution was disposed in the drain.

To achieve the best management of dental waste, minimization, segregation, reuse and recycling program should be implemented as much as possible. Waste reduction must be carried out using less hazardous and toxic materials with a smaller amount of packaging. For instance, installation of amalgam traps and application of small size capsules can minimize amalgam waste. Waste reuse can be achieved using reusable material and equipment instead of the disposable ones. On the other 
hand, the first priority in dental offices is the health and safety of the patients. Therefore, it is very important that using reusable material would not threaten patients' health. Prevention of mixing different fractions of dental waste has a significant role in dental waste management. For proper management of office general wastes, the staffs should not dispose these wastes along with the potentially infectious waste. Infectious waste must be separated from other dental wastes and disposed after sterilization using autoclave. Toxic and chemical and pharmaceutical wastes constituted about $20 \%$ of the total waste (Fig. 2). It is also suggested that toxic and chemical and pharmaceutical wastes should be separated from dental waste stream. For the best management of dental waste in Greece and Turkey, the researchers recommended that the dental waste must be sterilized and landfilled after source separation of lead foil and amalgam $[8,20]$.

In India, dentists pay no attention to waste management because they have no knowledge regarding waste management program [22]. Bdour et al. [27] reported that one of the main reasons for unsuitable waste collection and disposal in health care centers is the lack of specific regulations and guidelines for the waste separation and classification. The presence of a comprehensive plan for dental waste management is necessary to increase the awareness of dentists on the hazardous waste issue. Therefore, it is suggested that education of dentists for improvement of their knowledge on dental waste management should be considered as much as possible.

\section{Conclusion}

Total dental waste generation in all general dental offices, specialist dental offices and dental clinics were 58.94, 17.92 and $10.22 \mathrm{~kg} / \mathrm{day}$, respectively. Domestic, potentially infectious, toxic and chemical \& pharmaceutical waste also constituted $35.46,34.24,11.83$ and $5.56 \%$ of total waste, respectively. For the best management of dental waste, source reduction, separation, reuse and recycling program should be done. It is also suggested that, after source separation of the waste stream, each fraction of dental waste should be collected and separately disposed in accordance with its related criteria.

Acknowledgments Authors would like to acknowledge deputy of research of Urmia University of Medical Sciences for funding this research. The authors also thank the dentists of dental offices and clinics for the cooperation in this study.

Open Access This article is distributed under the terms of the Creative Commons Attribution License which permits any use, distribution, and reproduction in any medium, provided the original author(s) and the source are credited.

\section{References}

1. World Health Organization (2004) Review of health impacts from microbiological hazards in health-care wastes. WHO, Geneva

2. Koolivand A, Mahvi AH, Alipoor V, Azizi K, Binavapour M (2012) Investigating composition and production rate of health care waste and associated management practices in Bandar Abbass, Iran. Waste Manag Res 30:601-606

3. Alagöz BAZ, Kocasoy G (2007) Treatment and disposal alternatives for health-care waste in developing countries: a case study in Istanbul, Turkey. Waste Manag Res 25:83-89

4. Abdulla F, Qdais HA, Rabi A (2008) Site investigation on medical waste management practices in Northern Jordan. Waste Manag 28:450-458

5. Mbongwe B, Mmereki BT, Magashula A (2008) Healthcare waste management: current practices in selected healthcare facilities, Botswana. Waste Manag 28(1):226-233

6. Hiltz M (2007) The environmental impact of dentistry. J Can Dent Assoc 73(1):59-62

7. Al-Rabeah A (2002) Infection control in the private dental sector in Riyadh. Ann Saudi Med 22(1):13-17

8. Kizlary E, Iosifidis N, Voudrias E, Panagiotakopoulos D (2005) Composition and production rate of dental solid waste in Xanthi, Greece: variability among dentist groups. Waste Manag 25:582-591

9. World Health Organization (2005) Management of solid healthcare waste at primary health-care centers: a decision-making guide. WHO, Geneva

10. Emin MB, SinanMB Erdog Tb (2009) Medical waste management in Turkey: a case study of Istanbul. Waste Manag 29:445-448

11. Verma LK, Mani Sh, Sinha N, Rana S (2008) Biomedical waste management in nursing homes and smaller hospitals in Delhi. Waste Manag 28(12):2723-2734

12. Shinee E, Gombojav E, Nishimura A, Hamajima N, Ito K (2008) Healthcare waste management in the capital city of Mongolia. Waste Manag 28(2):435-441

13. Jokstad A, Fan PL (2006) Amalgam waste management. Int Dent J 56(3):147-153

14. North Carolina Division of Pollution Prevention and Environmental Assistance. (2006) Dental waste management. Waste reduction fact sheet. http://www.p2pays.org/ref/01/00020.htm. Accessed 19 Feb 2006

15. Drummonda JL, Cailas MD, Croke K (2003) Mercury generation potential from dental waste amalgam. J Dent 31(7):493-501

16. Hylander LD, Lindvall A, Gahnberg L (2006) High mercury emissions from dental clinics despite amalgam separators. Sci Total Environ 362:74-84

17. Ismail AI (2006) Neurotoxicity of mercury in dental amalgam. J Am Med Assoc 296:1461-1462

18. Needleman HL (2006) Mercury in dental amalgam-a neurotoxic risk? J Am Med Assoc 295:1835-1836

19. Nabizadeh R, Koolivand A, Jonidi Jafari A, Yunesian M, Omrani $\mathrm{G}$ (2012) Composition and production rate of dental solid waste and associated management practices in Hamedan, Iran. Waste Manag Res 30:619-624

20. Ozbek M, Sanin FD (2004) A study of the dental solid waste produced in a school of dentistry in Turkey. Waste Manag 24(4):339-345

21. Vieira CD (2009) Composition analysis of dental solid waste in Brazil. Waste Manag 29(4):1388-1391

22. Sudhakar V, Chandrashekar J (2008) Dental health care waste disposal among private dental practices in Bangalore city, India. Int Dent J 58(1):51-54 
23. Darwish RO, Al-Khatib IA (2006) Evaluation of dental waste management in two cities in Palestine. East Mediterr Health J 12(Supp2):217-221

24. Nazar MW, Pordeus IA, Werneck MAF (2005) Dental waste management in municipal health clinics in Belo Horizonte, Brazil. Pan Am J Public Health 17(4):237-242

25. Kontogianni S, Xirogiannopoulou A, Karagiannidis A (2008) Investigating solid waste production and associated management practices in private dental units. Waste Manag 28(8):1441-1448
26. Environmental and Occupational Health Center (2013) A guide to waste classification for environmental health inspector. Ministry of Health of Iran, Tehran

27. Bdour A, Altabsheh B, Hadadin N, Al-Shareif M (2006) Assessment of medical wastes management practice: a case study of the northern part of Jordan. Waste Manag 27:727-728 